\title{
J(৫)
}

Received: 12.04 .2019

\section{Eski Türk Yazıt ve El Yazmalarında İkilemeler}

\section{Reduplications in the Old Turkic Inscriptions and Manuscripts}

\author{
Erhan AYDIN \\ Inönü University (Malatya/Turkey) \\ E-mail: erhan.aydin@inonu.edu.tr \\ Ahmet KARAMAN \\ Inönü University (Malatya/Turkey) \\ E-mail: karamana00@gmail.com
}

Reduplications or hendiadyoins are one of the important elements of the evolution and development of a language. They that appear in the first documents of the Turkish language from the 8th century onwards are a proof that Turkish has undergone inter-word interactions earlier than the 8th century. In this respect, it is an important requirement to identify the reduplications written in old Turkic scripts and manuscripts. In this article, all the inscriptions and manuscripts written in Old Turkic script will be examined and the hendiadyoins used will be determined.

Key Words: reduplications, Old Turkic inscriptions, old Turkic manuscripts. 


\section{$J(\Theta)$}

\section{Giriş}

Türklerin tespit edilebilmiş en eski yazılı kaynakları Eski Türk yazıtlarıdır. Eski Türk yazısıyla yazılmış olan bu yazıtlar, Türklerin geniş bir alana yayılmış olmasina paralel olarak Moğolistan, Yenisey (Tuva ve Hakasya), Dağlık Altay Cumhuriyeti, Kırgizistan, Kazakistan ve Çin Halk Cumhuriyeti gibi çeşitli coğrafyalarda yer almaktadır. Eski Türk yazıtları, her şeyin kısa ömürlü olduğu Orta Asya bozkırında, sonsuzluğa taşınabilmesi adına, taşlara işlenmiştir.

Sözü edilen yazıtların en meşhurları, II. Türk Kağanlığı'na ait olup VIII. yüzyılda dikilmiştir. Bu yazıtlar bugün Moğolistan'da bulunmaktadır. Köl Tegin, Bilge Kağan, Tonyukuk, Ongi ve Küli Çor yazıtları bu yazıtların en hacimli olanlarıdır. Bu yazıtlar, Türk adının geçtiği ilk yazılı metinler olmanın yanında, ilk Türk tarihi olma özelliğine de sahiptir. Aynı zamanda Türk dilinin ilk edebî eserleri de yine bu yazıtlardır.

Türklere ait ilk yazılı kaynaklardan bir kısmı ise Yenisey bölgesinde bulunmaktadır. Yenisey yazıtları ifadesiyle, daha çok, bugünkü Tuva ve Hakasya sınırları içerisinde ele geçmiş yazıtlar anlaşılmaktadır. Bu yazıtların hangi tarihlerde dikildiği henüz tespit edilememiştir. ${ }^{1}$ Yenisey bölgesindeki yazıtlar, Moğolistan yazıtlarından daha önce bulunmuş olmasına karşın, gerek mezar yazıları olmasından kaynaklı kalıplaşmış ifadelerden teşekkül etmesi gerekse de satır sayısı olarak Moğolistan yazıtlarından daha sınırlı olmasından ötürü geri planda kalmıştır.

II. Türk Kağanlığı'na karşı, Basmıl ve Karluk boylarını yanlarına alarak isyan edip Ötüken merkezli bağımsız bir kağanlık kuran Uygurlar da eski Türk yazısıyla yazılmış bazı yazıtlar bırakmışlardır. Bunlar; Tes, Tariat (Terh), Şine Usu, Sevrey, Karı Çor (Xi'an), Hoyto-Tamır, I. Karabalgasun, Suci, II. Karabalgasun, Arhanan ve Gurvaljin-uul yazıtlarıdır. Söz konusu yazıtlar arasında daha hacimli olan Tes, Tariat ve Şine Usu yazıtlarında esasen II. Türk Kağanlığı'nın çöküşü ile diğer Türk boyları ve bozkır kavimleriyle yaşanan hâkimiyet mücadelesi anlatılmaktadır.

Yenisey yazıtlarının tarihlendirilmesi konusunda çeşitli görüşler bulunmaktadır. Konu ile ilgili daha fazla bilgi için bk. Bazin 2011: 88-117 ve Aydın 2012. 


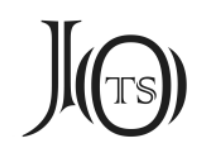

Genel hatlarıyla yukarıda belirtilen bu Eski Türk yazısıyla yazılmış Eski Türk yazıtları üzerine geçmişten günümüze pek çok konuda araştırma yapılmıştır. Gerek okuma gerek anlamlandırma gerekse de dilbilgisi konuları üzerine yapılan çalışmalar günümüzde de devam etmektedir. Metinlerin doğru okunması ve anlamlandırılması sürecinden başlayarak, söz dizimi, sözlük bilimi, sözcük yapımı ve diğer bazı dilbilgisi ve anlambilim incelemelerini gerektiren bir başka araştırma konusu da ikilemelerdir.

İkileme, anlatılmak istenen duygu ve düşüncelerin aktarım gücünü artırmak, anlatımı/anlamı kolaylaştırmak/pekiştirmek, kavramı zenginleştirmek gibi amaçlarla, aynı sözcüğün tekrar edilmesi veya yakın anlamlı yahut zıt anlamlı ya da sesleri birbirine benzeyen iki veya daha fazla sözcüğün yan yana kullanılmasıdır. İkilemeyi oluşturan sözcükler arasında, anlam ya da ses yönünden benzerlikler bulunmaktadır ve ikilemeler en az iki sözcükten teşekkül etmektedir. Anlamın pekiştirilmesi ve zenginleştirilmesi bir yana, dillerin, evrendeki sonsuz sayıdaki varlıkları karşılamak için başvurdukları yöntemler açısından bakıldığında, ikilemeler daha dikkat çekici bir hâl almaktadır. Çünkü kimi ikilemeleri oluşturan sözcükler, zaman içerisinde ayrı ayrı karşıladıkları anlamları yitirerek, tek ve yeni bir anlama bürünebilmektedir. Böylece dil, evrendeki sayısız varlığa, bünyesindeki malzemeyi kullanarak yeni karşlıklar bulma imkânına kavuşmaktadır. Bu tip anlam değişmeleri, soyutlaşmalar ve mecazî kullanımlar, bir dilin ne kadar işlendiğini, olgunlaştığını göstermektedir. Nitekim bu çalışmada incelenen malzemenin bir bölümünün VIII. yüzyıldan kalma yazıtlar olduğu düşünüldüğünde, daha o dönemden Türk dilinin olgunluğu gözler önüne serilmektedir. Dahası, ilişkide olduğu dillere oranla, Türk dili daha fazla ikilemeyi bünyesinde barındirmaktadır.

İkilemelerin bir başka fonksiyonu da hiç şüphe yok ki sözü güzelleştirmesidir. Aralarında ses benzerliği bulunan ikilemeler, konuşma ve günlük yazı dilinde dahi ahenkli bir söyleyişi mümkün kılmaktadır.

İkileme, Almancada, verdoppelung, zwillingsformen, hendiadyoin; Fransızcada, redoublement, hendiadyoin; İngilizcede, reduplication, reduplication dual, hendiadyoin; Rusçada, reduplikatsiya, povtor udvoyeniye (Rozental-Telenkova 1976), parniye 


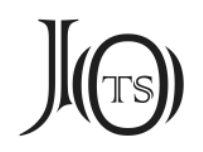

slova (Baskakov 1947: 244); Osmanlı Türkçesinde, atf-ı tefsiri, terkibi-i ihmâli, mühmelât terimleriyle karşılanmaktadır. Türkiye'de yapılan çeşitli araştırmalarda ikileme için "kelime koşmaları, tekrarlar, ikileme-ikizleme, bağlam öbekleri (ikilemeler, koşma takımları), tekrarlama, tekrar grubu, tekrar öbeği, tekrarl yapı sinıfları" gibi terimler kullanılmıștır.

Türk dilinde bulunan ikilemeler hakkında ilk bilgiler Kâşgarlı Mahmud tarafından verilmiştir. Kâşgarlı Mahmud, Dîvânu Lugâti't-Türk'te şu ifadelere yer verir:

Bil ki Oğuzca tuhaftır. Çift olarak kullanılan bu isim ve fiillerden biri asıldır, diğeri de onun şubesidir veya ona bağlıdır. Onlar (Oğuzlar), Türklerden farklı olarak, tâbi olan kelimeyi tek başına kullanırlar. Örneği şudur: Türkler, bir şey diğer bir şeye katıldı̆̆ı zaman, kattı kardı derler. Bir şeyi bir şeye katmakta asıl olan kattı'dır; kardı, ona tâbidir. Oğuzlar ise bir şeyi bir şeye katmak için kardı derler ve aslını (kattı'yı) bırakırlar. Bunun gibi Türkler edgü yawlak derler; edgü 'iyi'dir, yawlak 'kötü’dür; eḍü ile birlikte kullanılır; yalnız başına kullanılmaz. Oğuzlar ise onu tek başına kullanırlar (Ercilasun-Akkoyunlu 2015: 187).

İkilemeler üzerine Türkiye'de pek çok çalışma yapılmıştır. Bu çalışmanın malzemesinin Eski Türk yazısıyla yazılmış yazıtlar ve el yazmaları olması sebebiyle, burada Türkiye Türkçesindeki ikilemeler üzerine yapılmış çalışmalara ana hatları ile değinmek yeterli olacaktır. Türkiye'de ikilemeler konusundaki ilk çalışmalar için Foy 1899, Ağakay 1953a, 1953b, Hatipoğlu 1981 ve Tuna 1986 sayılabilir. Ayrıca, Zeynep KoRKMAZ, Tahir N. GENCAN, Muharrem ERGiN, Tahsin BANGUOĞLU, Leyla KARAHAN gibi dilbilgisi çalışmaları yapan araştırmacılar da ikilemeler üzerine görüş belirtmişlerdir. Bunlara ek olarak Necmi AKYALÇıN tarafından, alfabetik olarak hazırlanan Türkçe İkilemeler Sözlüğü (2007) adlı eseri de anmak gerekir.

Eski Türkçe dönemine ait eserlerdeki ikilemeler üzerine yapılmış çalışmalara bakıldığında, Çağatay 1944, Aydın 1997, Şen 2002, Ölmez 1997, 1998, 2017, Sev 2004, Erdem 2005, Aktan 2010, Taş 2012 gibi çalışmaların yapıldığını söyleyebiliriz.

Sözcük ve sözcük gruplarının bağlam içerisindeki yerinin dikkatli bir şekilde incelenmemesi, bazı anlamsal sorunlara yol açmaktadır. Bu sebepten ötürü, incelenen sözcük veya sözcük gruplarının geçtiği cümlelerin, bu tip çalışmalarda 


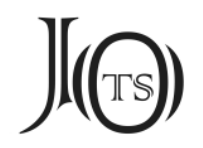

yer alması gerekmektedir. Bu bakımdan, bu yazıda ikilemelerin bulunduğu örnek cümlelere yer verilecektir. Aynı zamanda ikilemelerin geçtiği cümlelerin, hangi yazıtın hangi satırında olduğu da belirtilecektir. Bununla birlikte, yer verilen ikilemelerin daha kolay algılanabilmesi için ikilemeler, koyu renkle gösterilecek böylece algıda seçicilik de sağlanmış olacaktır. Örneğin:

eçü apa 'ata ced'

[...] kişi oglınta üze eçüm apam bumın kagan istemi kagan olormış [...] (KT D1)

[...] türük törösin ıçgınmış bodunug eçüm apam törösinçe yaratmış boşgurmış [...] (KT D13)

İkilemelerin geçtiği cümlelerin tamamı alınmak yerine, anlamsal bütünlügün sağlandığı kısımları almakla yetinilecektir. Bunun yapılmasındaki amaç, gereksiz bir hacim oluşmasına engel olmaktır. İkilemeler yalnızca alfabetik bir s1rayla verilmeyecek aynı zamanda anlamsal bir tasnif de yapılacaktır. Bu tasnif, eş anlamlı sözcüklerden oluşanlar, yakın anlamlı sözcüklerden oluşanlar ve zıt anlamlı sözcüklerden oluşanlar biçiminde olacaktır.

İkilemelerdeki tanıklar için verilen örnekler, Aydın 2017, 2018, 2019 ile T1bıkova et al. 2012, Yıldırım 2017 ve Alimov 2014’ten alınmıştır.

\section{Eş Anlamlı Sözcüklerden Oluşan İkilemeler}

Bu tür ikilemelerde, ikilemeyi oluşturan sözcüklerin her ikisi de aynı anlamdadır:

\section{1. arkış térkiş 'kervan'}

[...] ötüken yér olorup arkış térkiş ısar ney buyug yok [...] (KT G8)

[...] ötüken yér o[lo]rup [arkış] térkiş ısar ney bu[yug yo]k [...] (BK K6)

\section{2. at kü 'ad, san/şan, şöhret'}

[...] türük bodunug atı küsi yok bolmazun téyin kanım kaganıg ögüm katunug kötürmiş teyri él bérigme teyri türük bodun atı küsi yok bolmazun [téyin özümün ol teyri] (KT D25)

[...] kayımız éçimiz kaz[ganmış bodun atı küsi yok bolmazun] (KT D26) 


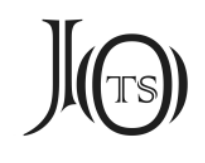

[...] türük bodun atı küsi yok bolmazun téyin kayım kaganıg [...] (BK D20)

[...] kayım kaganıg ögüm katunug kötürügme teyri él bérig[me te]yri türük bodun atı küsi yok bolmazun téyin özümün ol teyri olortdı [...] (BK D21)

[...] éçimiz kazganmış bodun atı küsi yok bolmazun téyin [...] (BK D22)

yazukl<...> [b]érye tawgaçda atı küsi yok boltı [...] (BK D36)

\section{3. at yol 'ad, san'}

[...] bunça bodunug atın yolın ayıgma [...] (Ta K5)

\section{4. bay bar 'zengin, varlıklı'}

tegdi bay bar ertim [...] (Su 5)

[...] bay bar e<r>tim [...] (Novosyolovo (E 144) 2)

\section{5. bodun bokun / bukan 'halk, millet'}

bodunum bokunum (bukanım ?) a bökmedim yıta esizim e [...] (Yeerbek I (E 147) 5)

bo]dunı : bokunı ${ }^{2}$ : tir[...] ka]nlık : erig : (é)liti : udu : yetip [...] (O. 1; A (B?) Yüzü 1-2)

\section{6. bök ulug 'yüce, büyük'}

[...] bök ulug kagan [ermiş] (Tes K1)

\section{7. eçü apa 'ata, ced'}

[...] kişi oglınta üze eçüm apam bumın kagan istemi kagan olormış [...] (KT D1)

[...] türük törösin ıçgınmış bodunug eçüm apam törösinçe yaratmış boşgurmış [...] (KT D13)

[...] eçümüz apamız tutmış yér suw idisiz bolmazun téyin [...] (KT D19)

kişi oglınta üze eçüm apam bumın kagan istemi kagan olormış [...] (BK D3)

2 Rusya'da bulunan Eski Türk yazılı metin parçalarından olan O. 1'deki söz konusu ifadenin harf çevrimi şu şekildedir: ... $d^{1} U n^{1} I: b^{1} U k^{1} U n^{1} I: t^{2} I^{2}[\ldots$ 


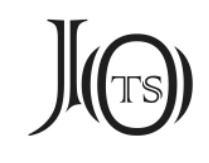

bodunug eçüm apam törösinçe yaratmış boşgurmış [...] (BK D12)

[...] eçü[müz apamız tutmış yé]r suw [idi]siz bolmazun [téyi]n [...] (BK D16)

eçümüz apamız yamı kagan tört bulunug étmiş [...] (O D1)

<...> eçüm apam sekiz on yıl olormış [...] (Ta D3)

$[. .]<.\ldots$... [b]éş seyüt kara bodun turuyun kanım kanka ötünti eçü apa atı (Ta G4)

\section{8. edgüti katıgdı 'iyice, sıkıca'}

[...] bo sawımın edgüti éşid katıgdı tınla [...] (KT G2)

[...] bo sawımın edgüti éşid katıgdı tı̣la [...] (BK K1)

\section{9. ey mey 'av'}

bars : kéyik : ejke : meyke : barmış : eyin : menin : bulmış [...] (IB, 31)

\subsection{0. eyle- meyle- '(vahşi hayvan) avlamaya çıkmak'}

bars : kéyik : enleyü : menleyü : barmış [...] (IB, 49)

\subsection{1. ertin- ökün- 'pişman olmak'}

[...] türük bodun ertin ökün küregüyün üçün igidmiş kagayına [...] (BK D19)

\subsection{2. esen tükel 'sağ salim, sapasağlam'}

[...] teyri : kutınta : üçünç : yılta : kop : esen : tükel : körüşmiş [...] $(\mathrm{IB}, 15)$

[...] bay : er : koñ : ürküpen : barmış : börike : sokuşmış : böri : agzı : emsimiş : esen : tükel : bolmış [...] (IB, 27)

[...] idişin : ayakın : esen : tükel : bulmış : ögirer : sewinür [...] (IB, 42)

\subsection{3. ew bark 'ev, bark'}

<...> birle ko(ŞU totok birle sünüşmiş erin kop ölürmiş ewin bar[kın <...> kop kelürti [...] (KT K1) 


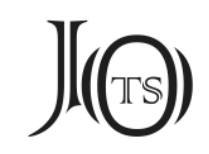

ewin barkın buzdum o[gu]z bodun tokuz tatar birle térilip kelti [...] (BK D34)

[...] karagan kısılta ewin barkın anta buzdum [...] (BK D37)

[...] ewin barkın yılkısın [y]ulımadım [...] (ŞU D2)

$<. . .>$ ew barkınt[a] ermiş [...] (ŞU D12)

[...] katıg taşıg ewig barkıg [tokıtdım?] [...] (Olon-Nuur, Doğudaki Taş Blok Üzerindeki Metin, 2)

\subsection{4. éşid- tı̣la- 'işitmek, dinlemek'}

[...] bo sawımın edgüti éşid katıgdı tınla [...] (KT G2, BK K1)

\subsection{5. ét- yarat- 'düzenlemek, örgütlemek'}

[...] yér suw idisiz bolmazun téyin az bodunug étip yar[atıp] <...> (KT D19)

[...] kögmen yér suw idisiz bolmazun téyin az kırkız bodunug <étip> yarat [1p]<...> (KT D20)

[...] kögmen yér suw idisiz bolmazun téyin az kırkız bodunug [étip] yaratıp [...] (BK D17)

[...] bodunug nençe étm[iş nençe yaratmış te]yr[i] yarlıkad[ok ü]ç[ün] özüm olortokuma tör[t] b[uluydakı bo]dunug éttim yara[t]dım [...] (BK K9)

\subsection{6. idiş ayak 'kap kacak'}

uzuntonlug : idişin : ayakın : kodupan : barmış : yana : edgüti : sakınmış : idişimte : ayakımta : öni : kança : barır : men : tér : yana : kelmiş : idiş̧in : ayakın : esen : tükel : bulmış [...] (IB, 42)

\subsection{7. kadaş kin 'yakın akraba'}

kadaşım a kinim e adrıltım e yıta [...] (Elegest I (E 10) 12)

kadaşım <a> kinim e yıta adrıltım [...] (Kızıl-Çıraa II (E 44) 4)

\subsection{8. katıgtı edgüti 'sıkıca, iyice'}

kuzgunug : 1gaçka : bamış : katıgtı : ba : edgüti : ba : tér : ança : bilinler (IB, 14) 


\section{J(G)}

\subsection{9. kut ülüg 'talih, kısmet'}

[...] teyri yarlıkadok üçün kutum ülügüm bar üçün [...] (BK D23)

\section{20. kü küç 'güç kuvvet'}

[...] bolayın : tenrim : küsi : küçi : ulug : kut : bérzün [...] (U 181 (T II T) 4-5)

\subsection{1. kü sorug 'şan, şöhret'}

küm sorugum kün tugsuka <kün> batsıka (Su 4)

\subsection{2. ney ney 'ne kadar'}

ney ney sawım <bar> erser [...] (KT G11)

ney ney sawım [bar erse]r [...] (BK K8)

\subsection{3. otça borça 'ateş gibi kor gibi'}

[...] türgéş kagan süsi bulçuda otça borça kelti [...] (KT D37)

[...] türgéş kagan süsi bulçuda otça borça kelti (BK D27)

\subsection{4. ögir- sewin- 'sevinmek, neşelenmek'}

[...] türük begler bod[un ö]girip sewinip tonıtmış közi yügerü körti [...] (BK D2)

[...] kara bodun kaganım kelti tép ög[irip sewinti] [...] (BK D41)

[...] kop : esen : tükel : körüşmiş : kop : ögirer : sevinür [...] (IB, 15)

çıgañ : er : oglı : kazgançka : barmış : yolı : yaramış : ögire : sevinü : kelir : [...] (IB, 30)

[...] bulupan : uyasıyaru : ögire : sevinü : kelir [...] (IB, 31)

[...] özi : süsi : ögire : sevinü : ordosınaru : kelir [...] (IB, 34)

[...] ögine : kanına : tegürmiş : ögi : kạı : ögirer : sevinür [...] (IB, 35)

[...] idişin : ayakın : esen : tükel : bulmış : ögirer : sevinür [...] (IB, 42)

[...] ölümte : ozupan : ögire : sevinü : yorıur [...] (IB, 49) 


\section{$J(\Theta)$}

\subsection{5. ögün- sevin- 'sevinmek'}

[...] (e)lt(ä)r(i)ş k(a)g(a)nka (i)ç(i)<k(i)n> ög(ü)ni s(ä)b(i)nü b(a)r(1)n [...] (Ç, (1) U st sağ) (Barutçu Özönder 2006: 113)

\subsection{6. öl- yit- 'ölmek, yitmek, mahvolmak'}

[...] kara bodunum öltüy yitdin yana içik ölmeçi yitmeçi sen tédim [...] (ŞU D5)

\subsection{7. ölü yitü 'öle, yite'}

[...] inim köl tegin birle éki şad birle ölü yitü kazgantım [...] (KT D27)

barmış bodun ölü yitü yadagın yalayın yana kelti [...] (KT D28)

[...] inim köl t[égin] birle éki şad birle ölü yitü kazgantım [...] (BK D22)

[...] yér sayu barmış bodun [yadagın yalayın] ölü yitü <...> (BK D22)

\subsection{8. söz sav 'haber'}

er : terkleyü : kelir : edgü : söz : sav : életi : kelir : tér : ança : bilinler : edgü : ol : (IB, 7)

sarıg : atlıg : savç : yagız : atlıg : yalawaç : edgü : söz : sav : életi : kelir : tér : ança : biliy :

añig : edgü : ol : (IB, 11)

\subsection{9. tewlig kürlüg armakçı 'hilekâr, sahtekâr, aldatıc1'}

[...] tawgaç bodun tewligin kürlüg<in> üçün armakçısın üçün [...] (KT D6)

[...] tawgaç bodun tew1[igin] kürlügin [üçün armakç1]sin üçün [...] (BK D6)

\subsection{0. tér- kuwrat- 'derlemek, toplamak'}

[...] ilgerü kurıgaru sülep té[r]miş (?) kuwratmış [...] (KT D12)

[...] ilgerü kurıgaru sülep térmiş kuwratmış [...] (BK D11)

[...] tokuz oguz bodunumun térü kuwratı altım [...] (ŞU K5)

\subsection{1. toru ölü 'yarı ölü yarı diri, bitkin mecalsiz'}




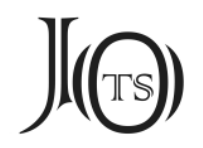

[...] anta kalmışı yér sayu kop toru ölü yorıyur ertig [...] (KT G9)

[...] anta kalm[1ş1] yér [say]u kop toru ölü yorıyur ertig [...] (BK K7)

\subsection{2. yayıl- yazın- 'yanılmak, hata yapmak'}

[...] türgéş kagan türüküm bodunum erti bilmedökin üçün bizine yayıltokın yazıntokın üçün kaganı öltti [...] (BK D16)

\subsection{3. yaş ot 'çayır, çimen'}

[...] yış : üze : yaş : ot : körüpen : yorıyu : barıpan [...] $(\mathrm{IB}, 17)$

\subsection{4. yawız bat 'kötü durumda, zayıf'}

yawız bat biz azıg üküşüg körtüg [...] (O D7)

\subsection{5. yawız yawlak 'kötü, perişan'}

[...] içre aşsız taşra tonsuz yawız yawlak bodunta üze olortum [...] (KT D26)

[...] içre aşsız taşra tonsuz yawız yawlak bodunta [üze olortum [...] (BK D21)

\subsection{6. yok çıgañ 'yoksul, fakir'}

yok çıgañ bodunug kop kuwrat<d>1m [...] (KT G10)

[...] yok çıgañ bodunug kop kuwratdım [...] (BK K7)

\section{Yakın Anlamlı Sözcüklerden Oluşan İkilemeler}

$\mathrm{Bu}$ tür ikilemeler, birbirine yakın anlamlı veya birbirini anlam olarak tamamlayan sözcüklerden oluşur:

\section{1. adrıl- seçlin- 'ayrılmak (ölmek)'}

adrıltım seçlintim yıta buy a (Kızıl-Çıraa I (E 43) 2)

\section{2. adrılma- azma- 'ayrılmamak, doğru yoldan sapmamak'}




\section{J(G)}

[...] teyri bilge kaganta adrılmalım azmalım téyin ança ütledim [...] (O K3)

\section{3. adrılma- seçlinme- 'ayrılmamak (ölmemek)'}

[...] ézençüm e küzençüm e adrılma seçlinme ögürdüm (Altın-Köl I (E 28) 6)

\section{4. alkın- arıl- 'yok olmak, mahvolmak'}

[...] kop anta alkıntıg arıltıg anta kalmışı yér sayu [...] (KT G9)

[...] kop anta alkıntıg arıl[tıg] anta kalm[ışı yér [say]u [...] (BK K7)

\section{5. alkın- yok bol- 'mahvolmak, yok olmak'}

[...] teyri öl témiş erinç türük bodun ölti alkıntı yok boltı [...] (T1 B3)

\section{6. alp erdem 'kahramanlık, yiğitlik'}

alp1 erdemi anta kükti [...] (KÇ B4)

[...] bilgesin üçün alpın erdemin [üçü]n kaz[g]ant < <... (KÇ B7)

<...> [taw]gaçka bunça sünüşüp alpın erdemin üçün kü bunça tutdı (KÇ B12)

<...>m üçün alpın üçün erdemin üçün (Uybat II (E 31) 2)

ant<a> él kızı erdim alp erd[em] <...> (El-Baj1 (E 68) 15)

özde oglum a esiz e alp erdemimdakı (Lisiç’ya I)

[...] kamuş : ara : başım : antag : alp : men : erdemlig : men [...] (IB, 10)

<..> özlüki boz at erti kedim <...> alpı erdemi anta kükdi (?) (KÇ B4)

<...> bilgesin üçün alpın erdemin [ü̧̈ü]n <...> (KÇ B7)

<...> [taw]gaçka bunça süyüşüp alpın erdemin üçün (KÇ B12)

\section{7. añı üz 'kötü, aksi'}

[...] apa tarkangaru içre saw ıdmış bilge toñukuk añıg ol üz ol [...] (T1 K10) 


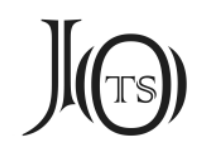

\section{8. ar- oy- 'yorulmak, bitkin düşmek'}

[...] özlük : at : öy : yérde : arıp : oyup : turu : kalmış [...] $(\mathrm{IB}, 17)$

\section{9. art- taş- 'artmak, çoğalmak'}

altun soya yış kéyiki artgıl taşgıl [...] (Altın-Köl I (E 28) 7)

\subsection{0. azıp kal- adrıl- 'çekip gitmek, ayrılmak, ölmek'}

élim utuşına azıp kala<y>ın adrılayın [...] (Elegest I (E 10) 9)

\subsection{1. edgü beni 'iyilik, mutluluk'}

<...> kagan élinte karıp edgü beyi körti [...] (KÇ B3)

\subsection{2. emgetme- tolgatma- 'eziyet, sıkıntı çektirmemek'}

$<\ldots>$ igidin emgetmey tolgatmay <...> [...] (BK K13)

\subsection{3. él törö 'ülke, yasa'}

[...] tawgaç kaganka élin törösin alı bérmiş [...] (KT D8)

ança kazganmış étmiş élimiz törömüz erti türük oguz begleri bodun éşidiy üze teyri basmasar asra yér telinmeser türük bodun élinin töröyün kim artatı <...> (KT D22)

[...] altı yégirmi yaşı๊a éçim kagan élin törösin ança kazgantı [...] (KT D31)

[...] bumın kagan istemi kagan olormış olorupan türük bodunuy élin törösin tuta bérmiş [...] (BK D3)

[...] tawgaç kaganka élin tör<ö>sin alı bérmiş [...] (BK D8)

[...] kayım [kagan élig törög kazganıp uça barmış] [...] (BK D13)

[...] ança kazganmış ança étmiş élimiz [törömüz erti türük oguz begleri bo]dun éşidin [...] (BK D18)

[...] üze teyri basmasar <asra> yér telinmeser türük bodun élinin törögin kim artatı [...] <..> (BK D19) 


\section{$J(\Theta)$}

[...] [élig törög] y[ég]di kazgantım [...] (BK D36)

[...] asra yagız yér igit<d>ök üçün élimin törömün étinti[m] [...] (Ta B3)

<..> yégen (?) érkin (?) élimin törömün kayım? (Hoyto-Tamır VII 3)

kara bodunum katıglanıy él törösin ıdmay [...] (Elegest I (E 10) 7)

él törü (Talas VI, Çiyin Taş A 1)

\subsection{4. élsire- kagansıra- 'yurdunu, kağanını kaybetmek'}

yéti yüz er bolmış yéti yüz er bolup élsiremiş kagansıramış bodunug [...] (KT D13)

[...] yéti yüz er bolmış yéti yüz er bolup él[siremiş kagansıramış bodunug [...] (BK D11)

\subsection{5. éş kadaş 'eş, dost, akraba'}

buy a éşim kadaşım yıta [...] (Çaa-Höl VI (E 18) 4)

\subsection{1 taş 'yazı, yaban'}

bod kalmadı ıda taşda kalmışı kuwranıp yéti yüz boltı [...] (T1 B4)

\subsection{7. içik- yükün- 'tâbi olmak, boyun eğmek'}

[...] kaganka kırkız bodunı içikdi yükünti [...] (T1 K4)

\subsection{8. ini éçi 'erkek kardeş, ağabey’}

[...] oglıtı kagan bolmış erinç anta [késre inisi éçisin teg [...] (KT D5)

[...] armakçısın üçün inili éçili kikşürtökin üçün begli bodunlug yoyaşurtokın üçün [...] (KT D6)

[...] inisi éçisin teg kılınmadok erinç oglı kayın teg [...] (BK D5)

[...] kürlügin [üçün armakçı]sın üçün inili [éçili kikşürtökin üçün begli bodunlug] [...] (BK D6)

[...] inisi éçisin bilmez erti oglı kayın bilmez erti [...] (BK D18)

inim éçim yıta adrılu bardımız yıta (Çaa-Höl VI (E 18) 2) 


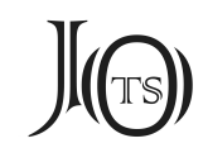

ininizke éçinizke ingen yüki éld<e> tüşürtünüz (Altın-Köl I (E 28) 3)

er er<d>em <ü>çün inim éçim uyurun üçün bengümün tike bérti (Altın-Köl I (E 28) 9)

[...]erim e inim e éçim e <...> bökmedim (Uybat III (E 32) 17)

\subsection{9. iş küç 'iş, güç'}

körmiş elig yıl işig küçüg bérmiş ilgerü kün tugsıkda [...] (KT D8)

[...] ne kaganka işig küçüg bérür men tér ermiş [...] (KT D9)

[...] bunça işig küçüg bértökgerü sakınmatı [...] (KT D10)

bodunug kop baz kıltım yag<1>sız kıltım kop maya körti işig küçüg bérür [...] (KT D30

[...] inim köl tégin <...> işig küçig bértök üçün türük bilge kagan [...] (KT B)

işig küçüg bérmiş ilgerü kün tugsıkda bükli kaganka tegi [...] (BK D8)

[...] ne kaganka işig küçüg bérür men tér ermiş [...] (BK D9)

[...] kızll kanım töküti kara terim yügürti işig küçüg bértim [...] (T2 D2)

[...] kayım baga tenriken yen anta yorımış işig küçin bérmiş erti <...> (O D5)

[...] teyri bilge kaganka sakınıp işig küçüg bérsigim bar ermiş erinç [...] (O K2)

[...] ög<g>en atka işig küçüg bérti (O K3)

tört bulundakı bodun <i>ş küç bérür [...] (Ta B4)

[...] işig küçüg bérgil tédim [...] (şU D5)

\subsection{0. kamşa- uma- 'hareket edememek, kımıldayamamak'}

[...] utru : yérde : ogrı : sokuşup : tutupan : minmiş : yéline : kudursugınına : tegi : yagrıpan : kamşayu : umatın : turur [...] (IB, 16)

bir : karı : öküzüg : bélin : biçe : kumursga : yémiş : kamşayu : umatın : turur : tér : ança : bilinler : yavlak : ol : (IB, 37)

tıgıg : tértrü : kişemiş : kamşayu : umatın : turur : tér : ança : bilinler : yavlak : ol : (IB, 39) 


\section{$J(\Theta)$}

\subsection{1. kat bük 'kıy1, bucak'}

ulug : ev : örtenmiş : katına : tegi : kalmadok : bükine : tegi : kodmadok : tér : ança : bilinler : yavlak : ol : (IB, 9)

\subsection{2. kazgan- ét- 'kazanmak, elde etmek'}

[...] kazganı bértim éti bértim <...> buysuz kıltım [...] (BK K12)

[...] ança kazganmış ança étmiş élimiz [törömüz erti türük oguz begleri bo]dun éşidin [...] (BK D18)

\subsection{3. kul kün 'erkek ve kadın köle’}

[...] kulum küyüm bodunug teyri (ŞU D1)

\subsection{4. köz kaş 'göz, kaş'}

[...] éki şad ulayu iniygünüm oglanım beglerim bodunum közi kaşı yawlak boltaçı tép sakıntım [...] (KT K11)

\subsection{5. kün kul 'kadın ve erkek köle'}

[...] özi yayıltı kaganı ölti bodunı küy kul boltı [...] (KT D20)

[...] özi yayıltı kaganı ölti bodunı küy kul boltı [...] (BK D17)

[...] künüm kulum bodunug teyri yér anta ayu [bé]rti [...] (ŞU G9)

\subsection{6. küyed- kulad- 'cariye, köle olmak'}

[...] élsiremiş kagansıramış bodunug küyedmiş kuladmış bodunug [...] (KT D13)

[...] él[siremiş kagansıramış bodunug küyedmiş kuladmış bodun]ug [...] (BK D11)

\subsection{7. otsuz suvsuz 'otsuz, susuz'}

kéyik : oglı : men : otsuz : suvsuz : kaltı : uyın : neçük : yorıyın : tér : ança : bilinler : yavız : ol : (IB, 45)

\subsection{8. ög kay 'ana, baba'}




\section{J(G)}

[...] kugu : kuş : kanatına : urup : anın : kalıyu : barıpan : ögine : kayına : tegürmiş : ögi : kayı

: ögirer : sevinür [...] $(\mathrm{IB}, 35)$

[...] oglı : öginte : kayınta : övkelepen : tezipen : barmış [...] (IB, 58)

\subsection{9. öl- yok bol- 'ölmek, yok olmak'}

[...] men iniligü bunça başlayu kazganmasar türük bodun ölteçi erti yok boltaçı erti [...] (BK D33)

\subsection{0. ölür- urugsırat- 'öldürmek, soyunu yok etmek'}

[...] türük bodun ölüreyin urugsıratayın tér ermiş [...] (KT D10)

[...] türük bodunug ölür[eyin urugsıra]tayın [tér ermiş üze] (BK D9)

\subsection{1. saw ötüg 'söz, dilek'}

<...> tatawı bodun tawgaç kaganka körti yalawaçı edgü sawı ötügi kelmez téyin [...] (BK D39)

\subsection{2. savçı yalavaç 'haberci, elçi'}

sarıg : atlıg : savçı : yagız : atlıg : yalawaç : edgü : söz : sav : életi : kelir : tér : ança : bilì : añig : edgü : ol : (IB, 11)

\subsection{3. sıgta- yogla- 'ağıt yakmak, yas tutmak'}

[...] üç kurıkan otuz tatar kıtañ tatawı bunça bodun kelipen sıgtamış yoglamış [...] (KT D4)

[...] üç kurıkan otuz tatar kıtañ tatawı bunça bodun kelipen sıgtamış yoglamış [...] (BK D5)

\subsection{4. uguş bodun 'soy, halk'}

[...] iniygünüm oglanım birki ugu(ŞUm [bodunum] [...] (KT G1)

[...] iniygünüm oglanım birki ugu(ŞUm bodunum [...] (BK K1)

bir kişi yayılsar uguşı bodunu böşüküye tegi kıdmaz ermiş [...] (KT G6)

bir kişi yayılsa[r] uguşı bodunu böş]üküne tegi kıdmaz [...] (BK K4)

[...] yégirmi yaşıma basmıl 1 dok <k>ut ugu(ŞUm bodun<um> erti [... ] (BK D25) 


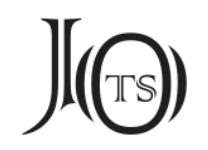

\subsection{5. yadag yalay 'yaya, yalın, çıplak'}

barmış bodun ölü yitü yadagın yalanın yana kelti [...] (KT D28)

[...] yér sayu barmış bodun [yadagın yalanın] ölü yitü <...> (BK D22)

\subsection{6. yayra- keyre- 'söylenmek, sizlanmak'}

uzuntonlug : közyüsin : kölke : ıçgınmış : yarın : yayrayur : kéçe : keyrenür : tér : ança : bilinler : muylug : ol : añig: yavlak : ol : (IB, 22)

\subsection{7. yarat- boşgur- 'örgütlemek, öğretmek'}

[...] türük törisin ıçgınmış bodunug eçüm apam törisinçe yaratmış boşgurmış [...] (KT D13)

bodunug eçüm apam törisinçe yaratmış boşgurmış [...] (BK D12)

\subsection{8. yér suw 'vatan, toprak'}

[...] eçümüz apamız tutmış yér suw idisiz bolmazun téyin [...] (KT D19)

[...] kögmen yér suw idisiz kalmazun téyin az kırkız [...] (KT D20)

[...] eçü[müz apamız tutmış yé]r suw [idi]siz bolmazun [téyi]n [...] (BK D16)

[...] kögmen yér suw idisiz kalmazun téyin az kırkız [...] (BK D17)

[...] tokuz oguz bodun yérin suwın ıdıp tawgaçgaru bardı [...] (BK D35)

<...> gakına? yérinerü suwıjaru kondı bérye karlok bodun tapa süle tép [...] (BK D40)

[...] ol yérimin suwumun konur köçür ben (Ta B4)

yérim e suwum a esizim e (Şançi III (E 152), 3)

\subsection{9. yogç1 sıgıtçı 'yasçı, ağıtçı'}

kergek bolmış yogçı sıgıtçı öyre kün tugsıkda [...] (KT D4)

[...] tép sakıntım yogçı sıgıtçı kitañ tatawı bodun başlayu [...] (KT K11)

yogçı sıgıtçı öyre kün tugsıkda büklü çöl<l>üg él [...] (BK D5) 


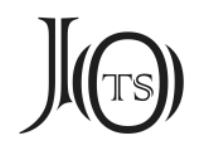

2.40. yurtda yolta 'orada burada'

[...] tirigi küy boltaçı erti ölügi yurtda yolta yatu kaltaçı ertigiz (KT K9)

\subsection{1. yüz beniz 'yüz, beniz'}

<...> [y]üz (?) er yüzi bin er benizi beglik kaş[1] [...] (Oçurı (E 26) 9)

\section{Zit Anlamlı Sözcüklerden Oluşanlar İkilemeler}

Bu tür ikilemeler, birbirinin karşıtı olan sözcüklerden oluşur:

\section{1. açsık tosık 'açlik, tokluk'}

[...] açsık tosık ömez sen bir todsar açsık ömez sen [...] (KT G8)

[...] açsar (açsık ?) tosık ömez sen bir todsar açsık ömez sen [...] (KT K6)

\section{2. antlig antsız 'antli, antsız'}

antlıg adaşım a antsızda edgü éşim e adrıltım a (Begre (E 11) 8)

\section{3. at- tut- 'atmak, tutmak'}

atsar alp ertiniz e tutsar küç ertiniz e [...] (Altın-Köl I (E 28) 5)

\section{4. az üküş 'az, çok'}

[...] çıgañ bodunug bay kıltım az bodunug üküş kıltım [...] (KT G10)

[...] yalay bodunug tonlug <kıltım> çıgañ bodunug bay kıltım az bodunug üküş kıltım [...] (KT D29)

[...] çıgañ bodunug bay kıltım az bodunug üküş kıltım [...] (BK K7)

[...] türük bodunug yiçe étdi yiçe igit<d>i çıgañıg bay kıltı azıg üküş kıltı [...] (BK D14)

[...] az bodunug üküş k1ltım ıgar élligde [1gar ka]ganlıkda [...] (BK D24)

yawız bat biz azıg üküşüg körtüg [...] (O D7) 


\section{J(৫)}

\section{5. bilir bilmez 'bilir, bilmez'}

[...] körür közüm körmez teg bilir biligim bilmez teg bolt1 [...] (KT K10)

\section{6. çıgañ bay 'yoksul, zengin'}

[...] çıgañ bodunug bay kıltım az bodunug üküş kıltım [...] (KT G10)

[...] yalay bodunug tonlug <kıltım> çıañ bodunug bay kıltım az bodunug üküş k1ltım [...] (KT D29)

[...] çıgañ bodunug bay kıltım az bodunug üküş kıltım [...] (BK K7)

[...] türük bodunug yiçe étdi yiçe igit<d>i çıgañıg bay kıltı azıg üküş kıltı [...] (BK D14)

[...] yalan bodunug tonlug <kıltım> çıgañ bodunug bay kıltım az bodunug üküş kıltım [...] $($ BK D23 = KT D29)

\section{7. er- bar- 'gelmek, gitmek'}

[...] köl tégin yéti otuz yaşıya karlok bodun erür barur erkli yagı boltı [...] (KT K1)

[...] karlok bodun buysuz erür barur erkli yagı boltı [...] (BK D29)

\section{8. ilgerü kurıgaru 'doğuya, batıya'}

[...] ilgerü kurıgaru sülep té[r]miş (?) kuwratmış [...] (KT D12)

[...] ilgerü kurıgaru sülep térmiş kuwratmış [...] (BK D11)

\section{9. kon- köç- 'konmak, göçmek'}

[...] ol yérimin suwumun konur köçür ben (Ta B4)

\subsection{0. köç- kon- 'göçmek, konmak'}

kan : süke : barmış : yagıg : sançmış : köçürü : konturu : kelir [...] (IB, 34)

\subsection{1. körür körmez 'görür, görmez'}

[...] körür közüm körmez teg bilir biligim bilmez teg bolt1 [...] (KT K10) 


\section{$J(\Theta)$}

\subsection{2. kün tün 'gündüz, gece'}

[...] kün yeme tün yeme yelü bardımız [...] (T1 K3)

\subsection{3. ot suw 'ateş su'}

[...] ança kazganıp birki bodunug ot suw kılmadım [...] (KT D27)

[...] ança kazganıp birki bodunug ot suw kılmadım [...] (BK D22)

\subsection{4. teyri yér 'gök, yer'}

[...] to[kuz ogu]z meniy bodunum erti tenri yér bulgakın üçün ödine (KT K4)

teyrideki künke yérdeki élimke bökmedim (Barı III (E 7) 3)

[...] kulum küyüm bodunug teyri yér ayu bérti anta sançdım [...] (ŞU D1-2)

[...] künüm kulum bodunug teyri yér anta ayu [bé]rti [...] (ŞU G9)

[...] üze : teprike : tegir : asra : yérke : kirür [...] (IB, 20)

\subsection{5. tün küntüz 'gece, gündüz'}

téyin türük bodun üçün tün udımadım küntüz olormad<ım> [...] (KT D27)

[...] yok bol[mazun] téyin türük bodun üçün tün udımadım küntüz olormadım [...] (BK D22)

[...] ol sawıg éşidip tün udısıkım kelmedi küntüz olorsıkım kelmedi [...] (T1 G5)

[...] <...>dı tün udımatı küntüz olormat1 [...] (T2 D1-2)

\subsection{6. tünle küntüz 'gece, gündüz'}

[...] ulug kut bérzün tü[n]le küntüz yorısar [...] (U 181/5-6)

\subsection{7. tün kün 'gece, gündüz'}

[...] ol sawın éşidip tün yeme udısıkım kelmez erti <kün yeme> olorsıkım kelmez erti [...] (T1 D5)

[...] tütünçs[üz : ot : yok : tüni : kü]ni : ök[ünç : yok [...] (Or. 8212/78 (Ch. 0014), B Fragmanı, A (B?) Yüzü 3-4) 


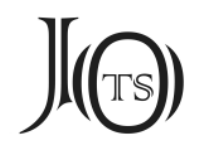

\subsection{8. tünli künli 'geceli gündüzlü'}

kök önüg yoguru sü yorıp tünli künli yéti ödüşke suwsuz keçtim [...] (BK G-D)

\subsection{9. ulug kiçig 'büyük, küçük'}

[...] esizim e ulugum <a> kiçigim e bökmedim e yita esizlerim e (Yeerbek I (E 147) 5)

\subsection{0. ürüy kara 'soylu, avam'}

[...] ürüyümüg e karamıg a azdım a (Begre (E 11), 3)

[...] ürünüm karam esiz yüz elig erim e esizim e (Köjeelig-Hovu (E 45) 7)

\subsection{1. yalay tonlug 'çıplak, giyimli'}

[...] yalay bodunug tonlug <k1ltım> çıgañ bodunug bay k1ttım az bodunug üküş k1ltım [...] (KT D29)

[...] yalay bodunug tonlug kıltım çıgañ bodunug bay kıltım (BK D23)

\subsection{2. yarın kéçe 'sabah, akşam'}

ten- : -si : men : yarın : kéçe : altun : örgin : üze : olurupan [...] (IB, 1)

ala : atlıg : yol : teyri : men : yarın : kéçe : eşür : men [...] (IB, 2)

[...] yarın : yayrayur : kéçe : keyrenür [...] (IB, 22)

\subsection{3. yér teyri 'yer, gök'}

[...] bilge ataçım yogun korugunun kazgantım <...> yér tẹri öd<...>ç kirür er $[\mathrm{ti}]<\ldots . .>(\mathrm{O} \mathrm{K} 4)$

$<\ldots>$ [yér] teyri kılıntokta uygur kagan olormış [...] (Tes K1)

[...] yér tey[ri] p ylsçbe(s?) [...] (Yır-Sayır II (E 94) 1) 


\section{$J(\Theta)$}

\section{Sonuç}

Diller, dış dünyada bulunan sonsuz sayıdaki varlığı karşılamak için çeşitli yöntemlere başvurur. Zira dil malzemeleri, bu sınırsız sayıdaki varlığı karşılamak üzere; sonsuz, birbirinden tamamen farklı ses ve anlam içeren kavram türetmekte yetersiz kalmaktadır. Dillerin başvurdukları bu yöntemlerden bazıları; sözcüklere eş anlamlılık, eş seslilik yüklenmesi ve mecazlı, yan anlatımların kazandırılmasıdır. Bu eş anlamlılık kimi durumlarda komşu dillerden sözcük ödünçlemeleri biçiminde gerçekleşmekte, kimi durumlarda ise o dilin öz sözcükleri üzerinden cereyan etmektedir. Bunların yanında bazı sözcükler de birbirine yakın anlamlar içermektedir. Bu anlamlar birbirinden küçük noktalarda ayrılır. Söz konusu dil olayları, dilin derinliğinin ve zamansal olarak uzun mesafeler aştığının birer göstergesidir.

Sözcüklerin mecazî anlam kazanmaları uzun süren bir süreci işaret etmektedir. Bu duruma benzer bir süreç ikilemeler konusu için de geçerlidir. Bazen ikilemeyi oluşturan öğeler gerçek anlamlarını yitirerek, anlamsal olarak ikilemenin içinde eriyerek bambaşka bir anlama kavuşmaktadır. Bunun nedeni ise dış dünyadaki sınırsız kavramın karşılanması zorunluluğudur. Bu zorunluluğun giderilmesinin yanında ikilemeler sözü güçlendirmekte aynı zamanda da ifadeyi güzelleştirmektedir. Kimi durumlarda sözcükler, gerçek anlamlarının dışında mecazî anlamlar kazanabilmekte kimi durumlarda ise ikileme oluşturabilmektedir.

İkilemeyi oluşturan sözcükler bazı teşkillerde öz anlamlarını ayrı ayrı koruyabilmekte bazı durumlarda ise bambaşka, yeni anlamlar kazanabilmektedir. Bu yazıda, tüm Eski Türk yazısıyla yazılmış yazıt ve el yazmaları incelenmiştir. II. Türk Kağanlığı, Uygur yazıtları, Yenisey Bölgesi, Dağlık Altay Cumhuriyeti, Kırgızistan, Moğolistan'daki diğer yazıtlar ve eski Türk yazısıyla kâğıda yazılmış el yazmaları çalışmanın kapsamına dâhil edilmiştir. İkilemeler tespit edilmekle yetinilmeyip, anlamsal çağrışımlarının da görülebilmesi için, ikilemelerin geçtiği cümleler de çalışmaya dâhil edilmiştir. Yapılan inceleme sonrasında, Eski Türk yazısıyla yazılmış tüm yazıtlar ve elyazlarında, eş anlamlı 36; yakın anlamlı 41; karşıt anlamlı ise 23 ikileme tespit edilmiştir. 


\section{J(৫)}

Araştırma sonucunda görüldügü üzere, kimi ikilemelerde, ikilemeyi meydana getiren öğelerin her ikisi de ek almazken, kimi ikilemelerde ise öğelerin her ikisi de ek almıştır:

Ek almamış olan ikilemelere birkaç örnek vermek gerekirse;

bay bar 'zengin, varlıklı', bök ulug 'yüce, büyük', añıg üz 'kötü, aksi 2 , ar- öy'yorulmak, bitkin düşmek', iş küç 'iş, güç', vs.

Her iki öğesi de ek almış örnekler:

yurtta yolta 'orada burada', yogçı sıgıtçı 'yasçı ağıtçı', yayra- kegre- 'söylenmek, sızlanmak', sıgta-yogla- 'ağıt yakmak, yas tutmak', ölür- urugsırat- 'öldürmek soyunu yok etmek'.

Eski Türk yazısıyla yazılmış yazıt ve el yazmalarımda geçen ikilemelere bakıldığında, hem isim soylu hem de fiil kökünden sözcüklerin ikileme teşkilinde kullanıldığı görülmektedir. İsim soylu sözcüklerle teşkil edilmiş ikilemelere birkaçörnek:

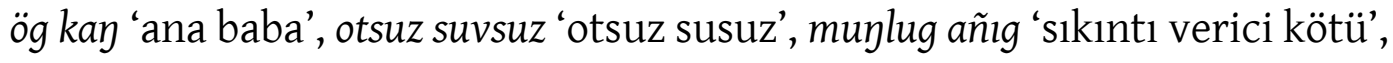
küg kul 'erkek ve kadın köle'.

Fiillerden oluşmuş ikilemelere örnekler:

küyed- kulad- 'cariye olmak, köle olmak', kamşa- uma- 'hareket edememek, kımıldayamamak', azıp kal-adrıl- 'çekip gitmek ayrılmak', adrıl- seçlin- 'ayrılmak, ölmek'.

Tüm bu tespitler sonrasinda görülüyor ki Türk dili, henüz VIII. yüzyılda dahi ikilemelere sık sık başvurmaktadır. Bu da Türkçenin VIII. yüzyıldan çok daha öncesinde, ikilemeleri bünyesinde bolca barındıracak olgunlukta bir dil olduğunu göstermektedir. Anlamın kuvvetlendirilmesi için teşkil edilmiş ikilemeler aynı zamanda ahenkli bir yapıya sahiptir. Kullanılan ikilemeler hem sözü güzelleştirmek hem de ifadeyi güçlendirmek fonksiyonlarını üstlenmiştir.

\section{Kisaltmalar}

$\mathrm{BK}=$ Bilge Kağan Yazıtı. 


\section{J(৫)}

Ç= Çoyr Yazıtı.

IB = Irk Bitig.

KarB II = II. Karabalgasun Yazıtı.

KÇ = Küli Çor Yazıtı.

KT = Köl Tegin Yazıtı.

$\mathrm{O}=$ Ongi Yazıtı

ON = Olon-Nuur Yazitı.

ŞU = Şine Usu Yazitı.

$\mathrm{Su}=$ Suci Yazıtı.

$\mathrm{T}=$ Tonyukuk Yazıtı.

$\mathrm{Ta}=$ Tariat $($ Terh) Yaziti.

\section{Kaynakça}

AĞAKAY, M. A. (1953a). “ikizlemeler Üzerine I”, Türk Dili, 16: 189-191.

AĞAKAY, M. A. (1953b). “ikizlemeler Üzerine II”, Türk Dili, 17: 268-271.

AĞAKAY, M. A. (1954). “Türkçede Kelime Koşmaları”, Türk Dili Araştırmaları Y1llığ1 Belleten 1954: 97-104.

AĞCA, F. (2015). "Eski Türkçe kö:k teyri ve kö:k kalık İkilemeleri Üzerine", Türkbilig, 30: 201-221.

AKTAN, B. (2008). “Divanü Lûgati't-Türk'ün Söz Varlığında Yer Alan İkilemeler", Selçuk Üniversitesi Türkiyat Araştırmaları Dergisi, 28: 1-12.

AKYALçIN, N. (2007). Türkçe İkilemeler Sözlüğü, Ankara: Anı.

Alımov, R. (2014). Tanrı Dağı Yazıtları, Eski Türk Runik Yazıtları Üzerine Bir İnceleme, Konya: Kömen.

AYDIN, E. (1997). “Orhon Yazıtlarında Hendiadyoinler”, Türk Dili, 577: 417421.

AYDIN, E. (2012). "Yenisey Yazıtları Nasıl Tarihlendirilebilir?", Turkish Studies, 7/2: 161-168. 


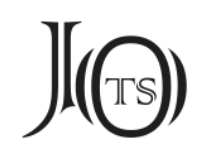

AYDIN, E. (2013). "Olon-Nuur/Galuut (Moğolistan) Yazıtı Üzerine Notlar", Bengü Belak, Ahmet Bican ERcilasun Armağanı, Ed. B. GÜL, Türk Kültürünü Araştırma Enstitüsü Yayınları, Ankara: 123-130.

AyDIN, E. (2017). Orhon Yazıtları Köl Tegin, Bilge Kağan, Tonyukuk, Ongi, Küli Çor, İstanbul: Bilge Kültür Sanat.

AYDIN, E. (2018). Uygur Yazıtları, İstanbul: Bilge Kültür Sanat.

AYDIN, E. (2019). Sibirya'da Türk İzleri, Yenisey Yazıtları, İstanbul: Kronik Kitap.

BARUTÇU-ÖZÖNDER, S. (2006). "Çöyr Yazıtı”, Modern Türklük Araştırmaları Dergisi, 3/3: 108-124.

BASKAKOV, N. A. \& T. M. ToşÇAKova (1947). Oyrotsko-Ruskiy Slovar, okolo 10000 slov, Moskova: OGIZ.

BAZIN, L. (2011). Eski Türk Dünyasında Kronoloji Yöntemleri, Çev. V. KöKEN, Ankara: Türk Dil Kurumu Yayınları.

BozoK, E. (2018). "Yazıtlarda Geçen 1da taşda İfadesinin Türkiye Türkçesinde ve Ağızlardaki Karşılıkları", Zeitschrift für die Welt der Türken, 10/3: 98-108.

ÇAĞATAY, S. (1944). "Uygurcadaki Hendiadyoinler”, Dil ve Tarih-Coğrafya Fakültesi Yıllık Çalışmalar Dergisi, 1: 97-144.

ERCILASUn, A. B. \& Z. AKKoYUnLU (2015). Kâşgarlı Mahmud Dîvânu Lugâti'tTürk (Giriş-Metin-Çeviri-Notlar-Dizin), 2. Baskı, Ankara: Türk Dil Kurumu Yayınları.

ERDEM, M. D. (2005). Harezm Türkçesinde İkilemeler ve Yinelemeler Üzerine, Bilig, 33: 189-225.

FoY, K. (1899). "Studien zur Osmanichen Syntax, das Hendiadyoin und die Wortfolge ana baba", Mitteilungen des Seminars für Orientalische Sprachen, 2/2: 105-136.

HATIPoĞLU, V. (1981). Türkçede İkilemeler, 2. Baskı, Ankara: Türk Dil Kurumu Yayınları. 


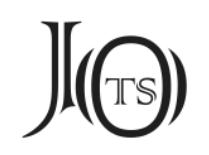

KaRAMAN, A. (2019). "Yenisey Yazıtlarında Geçen adrıl- seçlin- İkilemesi Üzerine”, Türk Dili Araştırmaları Yıllı̆̆ı Belleten, 67: 7-26.

KARGI-ÖLMEZ, Z. (1997). “Kutadgu Bilig'de İkilemeler (1)”, Türk Dilleri Araştırmaları, 7: 19-40.

KARGI-ÖLMEZ, Z. (1998). “Kutadgu Bilig'de İkilemeler (2)”, Bahşi Ögdisi, 60. Doğum Yılı Dolayısıyla Klaus RöHRBORN Armağanı, Eds. M. ÖLMEZ \& J. P. LAUT, Simurg, İstanbul-Freiburg: 237-234.

RozenTAL, D. \& M. A. Telenkova (1976). Slovar Spravoçnik, Lingvistiçeskih Terminov, Moskva: Prosveşçeniye.

ŞEN, S. (2002). Eski Uygur Türkçesinde İkilemeler, Ondokuz Mayıs Üniversitesi, Sosyal Bilimler Enstitüsü, Samsun. [Yayımlanmamış Yüksek Lisans Tezi]

ŞEN, S. (2015). “Tunyukuk Yazıtındaki ıda taşta İkilemesi Üzerine”, Dil Araştırmaları, 17: 95-102.

SEV, G. (2004). “Divanü Lûgati’t-Türk’te İkilemeler”, Türk Dili, 634: 497-510.

ŞIRIN, H. (2016). Eski Türk Yazıtları Söz Varlığı İncelemesi, Ankara: Türk Dil Kurumu Yayınları.

TAş, İ. (2012). "Kutadgu Bilig'de İkilemeler”, Türk Dili Araştırmaları Yılllı̆ı Belleten, 60/2: 43-95.

ÖLMEZ, M. (2017). “Eski Uygurca İkilemeler Üzerine”, Türk Dili Araştırmaları Yıllığ1 Belleten 65-2: 243-311.

Tibikova, L. N. et al. (2012). Katalog Drevnetyurkskih Runiçeskih Pamyatnikov, Gorno-Altaysk: Gorno-Altaysk Gosudarstvennıy Universitet.

TopraK, F. (2005). "Harezm Türkçesinde İkilemeler", Türk Dünyası İncelemeleri Dergisi, 5/2: 277-292.

TunA, O. N. (1983). “Türkçenin Sayıca Eş Heceli İkilemelerinde Sıralama Kuralları ve Tabiî Bir Ünsüz Dizisi”, Türk Dili Araştırmaları Yıllığı Belleten 19821983: 163-228. 


\section{J(৫)}

ÜstÜNOVA, K. (1998). Dede Korkut Destanlarında Aralıklı İkilemeler, Türk Dili, 557: 464-470.

YILDIRIM, F. (2017). Irk Bitig ve Orhon Yazılı Metinlerin Dili, Ankara: Türk Dil Kurumu Yayınları. 